\title{
Theoretical principles of creation of cellular concrete with the use of secondary raw materials and dispersed reinforcement
}

\author{
Eugene Pyataev ${ }^{1}$, Andrey Medvedev ${ }^{1 *}$, Alexey Poserenin ${ }^{2}$, Marina Burtseva ${ }^{1}$, Elizaveta \\ Mednikova ${ }^{1}$ and VitalyMukhametzyanov ${ }^{1}$ \\ ${ }^{1}$ Moscow State University of Civil Engineering, Yaroslavskoe shosse, 26, Moscow, 129337, Russia \\ ${ }^{2}$ Russian State Geological Prospecting University, Miklukcho-Maklaya, 23, Moscow, 117997, Russia
}

\begin{abstract}
The article outlines and substantiates the theoretical principles of the creation of cellular concrete reinforced with mineral fiber with the use of secondary products of housing renovation. The advantages provided by the dispersive reinforcement are the reduction in the economic costs of the construction of facilities, ensuring their reliable and durable operation. In this case, an important contribution is the alkali resistance of mineral fibers, the evaluation of which was carried out using the technique of an elemental composition based on the use of a spectrometer. On an example of research of technology of cellular concrete reinforced with alkaliresistant mineral fiber; Methods for evaluating the importance of factors characterizing technological processes, constructing polynomials of nonlinear regression, analytical optimization, selection of composition and evaluation of characteristics of raw components were tested. Reinforced with mineral fiber constructions can be built on weak grounds and effectively solve the problems of saving energy and raw materials.
\end{abstract}

\section{Introduction}

The aim of improving heat-insulating cellular concrete technology is to obtain products with average density of $100-200 \mathrm{~kg} / \mathrm{m} 3$, compressive strength of $0,4-0,6 \mathrm{MPa}$ and heat conductivity of $0,05-0,06 \mathrm{~W} /(\mathrm{m} \cdot \mathrm{K})$ in under factory conditions. Its would reduce a product cost by more than $40 \%$ and improve thermal efficiency. An average density of a products can be reduced by forming a high strength selicate stone and creation pore space structure characterized by uniform pore distribution.

Reduction of the average density of the products is achieved through the formation of silica rock of high strength and creation of the pore space structure, characterized by equal distribution of pores in the product and the rational ratio of cellular and capillary porosity [1-3]. It is technologically justified to use active mineral additives combined with efficient plasticizers and the concrete debris and other fine mineral commodities obtained when

* Corresponding author: medvedev747@yandex.ru 
implementing the Housing Renovation Program in particular. In spite of a number of indisputable advantages, unreinforced concrete is characterized by insufficient resistance impact, bending resistance. Moreover, shrinkage cracks can be formed during solidification. All of this lead to a relatively low durability of the products made of such concrete. These problems can be solved by secondary reinforcement (incl. dispersed reinforcement) using polypropylene, glass, basalt and metal fibers (Fig.1).

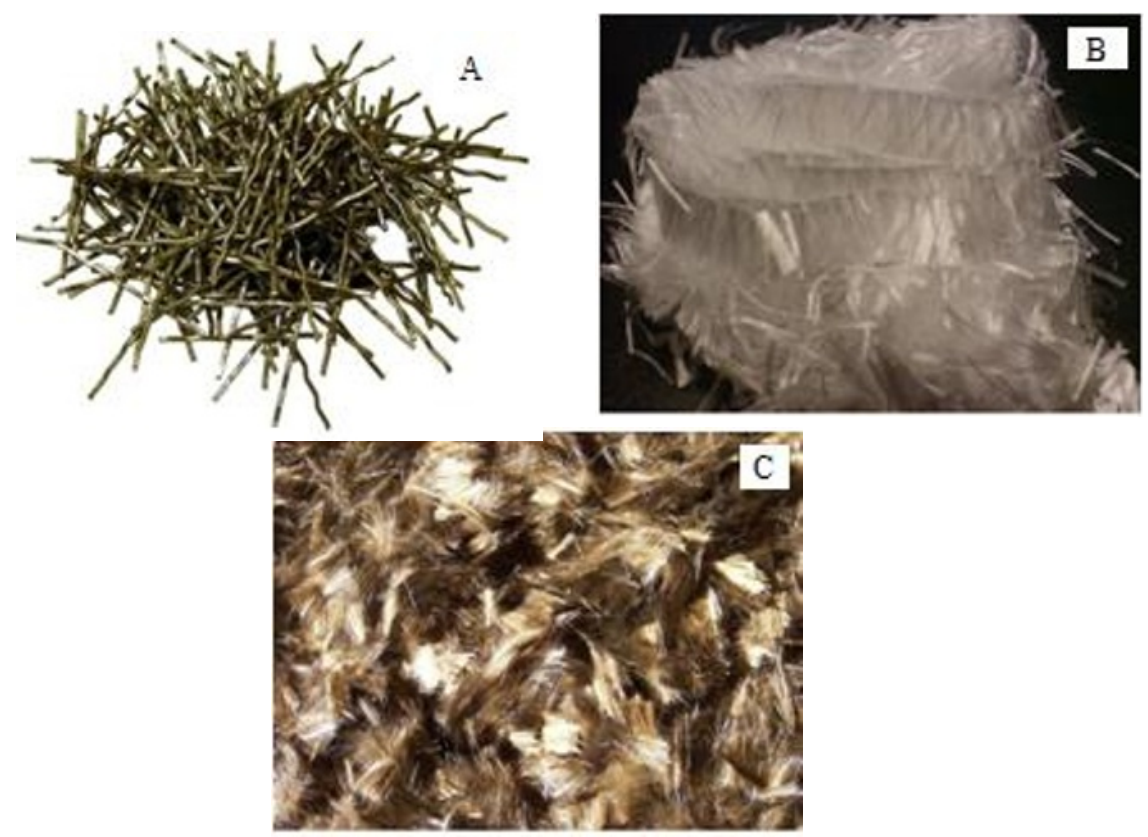

Fig.1. Reinforcing fiber: $\mathrm{a}$ - steel; $\mathrm{b}$ - polypropylene; $\mathrm{c}$ - basalt

These methods allow setting up complex constructions and solve the problem of low durability of the products. Dispersed reinforcement reduces the total weight of constructions. At certain proportioning the fiber replaces secondary reinforcement, reducing the usage of steel rebar. Dispersion reinforcement increases the plasticity of the concrete mixture and reduces the formation of shrinkage cracks. Unlike steel mesh, which is used only after the concrete has cracked, the fiber prevents cracks in the concrete at the stage when it is in a plastic state.

The products reinforced with polypropylene fibers are characterized by significant deformations even at low tensile loads, which is explained by the low adhesion of polypropylene in the cement matrix. In addition, such products lose their strength properties over time, have a high abradability of the surface and combustibility when an open flame affects fiber. The concrete products reinforced with basalt fiber or fiber on the basis of alkali-resistant stone wool do not have such disadvantages [4-6].

The experience of using mineral fibers (including basalt) has shown that it can be introduced into the foam concrete in the following way: the fiber is put into the concrete mixer in a dry mixture before adding water. For better distribution of fibers, it is necessary to put the fibers in the filler in parts during mixing; when mixing the fiber is added to the concrete in small portions directly into the mixer. Using this method, it is possible to achieve a more equal fiber distribution in the concrete. Fiber consumption per $1 \mathrm{~m} 3$ of concrete $(6 \mathrm{~mm}$ long) is $0.5-1 \mathrm{~kg}$. 
The concrete products reinforced with basalt fiber are characterized by increased durability, significant compressive strength, frost resistance, etc. The area of the contact between the fiber and the matrix is characterized by a dense contact between the surfaces and the absence of cracks and gaps (Fig.2).

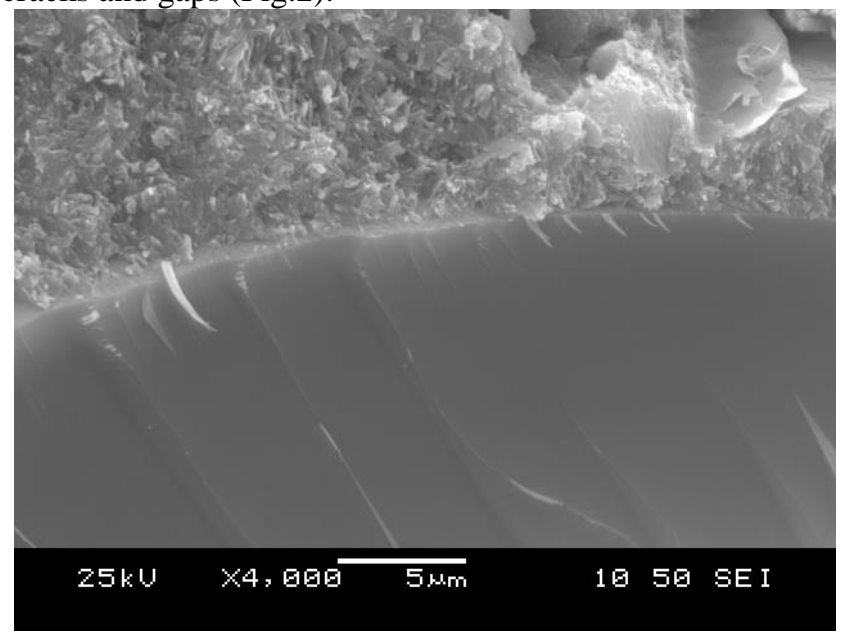

Fig. 2. Fiber-matrix interface

The solidifying concrete is considered to be a rather aggressive alkaline environment, which makes it necessary to evaluate the properties of the mineral fiber and its corrosion resistance. Due to the existing methods, including normative ones, the assessment of the fiber resistance is carried out by its acidity index which is equal to the ratio of acid $\left(\mathrm{SiO}_{2}+\mathrm{Al}_{2} \mathrm{O}_{3}\right)$ and basic oxides $(\mathrm{CaO}+\mathrm{MgO})$ contained in the fiber. It is considered that the higher the ratio, the more resistant to aggressive environments the fiber is. Nowadays the fibers are made with acidity index hesitating at 1,6-2,4. One of the factors of high resistance of mineral fibers is their elemental composition, and the content of heavy metals in particular.

\section{Experimental}

Determination of the elemental composition of stone wool samples was carried out by x-ray fluorescence analysis. The method is based on the excitation of atoms of the elements contained in the analyzed sample by the primary radiation of the source and the measurement of the intensity of the emerging characteristic x-ray radiation of excited atoms using spectrometry equipment.

The experiment was carried out using a spectrometer of the elemental composition of the substance "Respect", in the laboratory of physical methods of analysis of the Russian state geological prospecting University $[7,8]$.

As the primary exciting radiation in this device, the radiation of the $\mathrm{x}$-ray tube of the cross-section type with a silver anode is used. The maximum radiation power of the tube is $120 \mathrm{~W}$. In the analysis, a sample of rock wool weighing $1 \mathrm{~g}$ was placed in a cuvette with a base of a thin polypropylene film, the cuvette is placed in a carousel, designed for 16 samples (Fig. 3). 


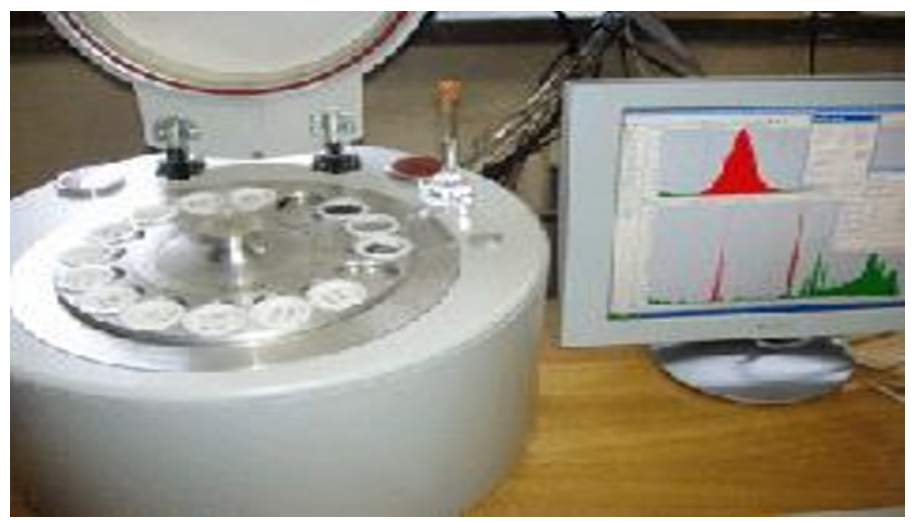

Fig. 3. Camera appearance with removable carousel

The accumulation and processing of spectrometric information is carried out by a personal computer with a built-in single-Board spectrometer, which also provides lowvoltage and high-voltage power to the detector. The x-ray spectrum processing program identifies the peaks of the elements and determines their areas, which are proportional to the concentrations of the analyzed elements. The result of processing is a file containing a list of elements that are part of the sample and their concentration [9-11]. Picture 4 shows the X-ray spectrum of a typical stone wool sample. In the sample established the presence of elevated concentrations of metals: $\mathrm{Ca}, \mathrm{Ti}, \mathrm{Mn}, \mathrm{Fe}$.

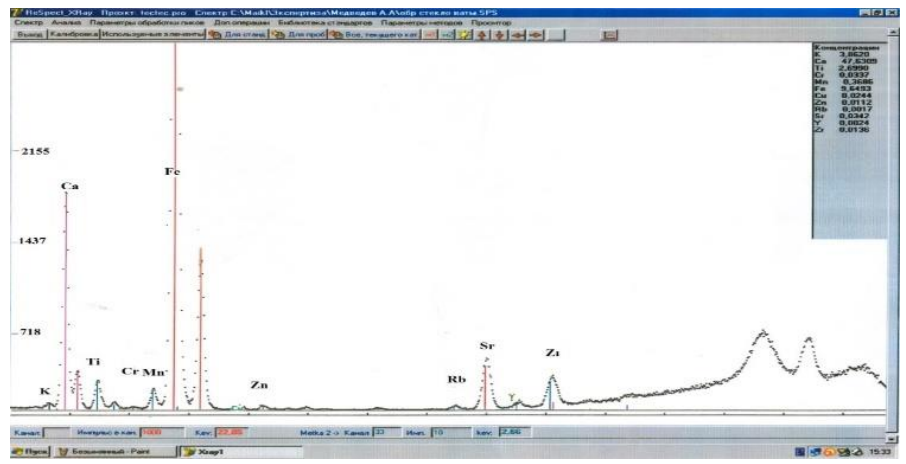

Fig. 4. The x-ray spectrum of a sample of stone wool

\section{Results \& Discussion}

Technological experiment (table.1) was aimed at optimizing the properties of raw materials and optimization of the composition of cellular fiber concrete using secondary raw materials, namely a complex additive including fine-milled active products of processing of concrete battle and superplasticizer. The technology of foam concrete of two-stage production is investigate well enough and its compounding passed wide approbation. The novelty consists in the use of stone fiber, so in the experiment this aspect of the technology was given special attention. As an optimization function, the following are accepted: Y1 average density of cellular fiber concrete, $\mathrm{kg} / \mathrm{m} 3$; Y2 - dencity of cellular fiber concrete under compression, MPa. 
Table 1. The conditions of the experiment

\begin{tabular}{|l|c|c|c|c|c|}
\hline \multicolumn{1}{|c|}{ Indicator } & $\begin{array}{c}\text { Symbol } \\
\mathbf{X}_{\mathbf{i}}\end{array}$ & $\begin{array}{c}\text { Average } \\
\text { value, } \\
\overline{\boldsymbol{X}}_{\mathbf{i}}\end{array}$ & \multicolumn{2}{|c|}{$\begin{array}{c}\text { The range of } \\
\text { variation, } \Delta \mathbf{X}_{\mathbf{i}}\end{array}$} & \multicolumn{2}{|c|}{$\begin{array}{c}\text { The value of the } \\
\text { indicator at levels }\end{array}$} \\
\cline { 4 - 6 } \\
\hline $\begin{array}{l}\text { The consumption of mineral } \\
\text { fibres, } \mathrm{kg} / \mathrm{m}^{3}\end{array}$ & $\mathrm{X}_{1}$ & 0,75 & 0,25 & 0,5 & 1,0 \\
\hline $\begin{array}{l}\text { The consumption of complex } \\
\text { additive, } \mathrm{kg} / \mathrm{m}^{3}\end{array}$ & $\mathrm{X}_{2}$ & 5 & 1 & 4 & 6 \\
\hline $\begin{array}{l}\text { The consumption of Portland } \\
\text { cement, } \mathrm{kg} / \mathrm{m}^{3}\end{array}$ & $\mathrm{X}_{3}$ & 265 & 25 & 240 & 290 \\
\hline $\begin{array}{l}\text { Foaming agent consumption, } \\
\mathrm{kg} / \mathrm{m}^{3}\end{array}$ & $\mathrm{X}_{4}$ & 10 & 2 & 8 & 12 \\
\hline
\end{tabular}

Statistical processing of the experimental results allowed to obtain the following dependencies:

1) For the average density of foam concrete reinforced by basalt fiber:

$$
Y_{1}=560-X_{1}-20 X_{2}-60 X_{4}+12 X_{2}^{2}
$$

The confidence interval calculated using the Student criterion and the dispersion of parallel experiments was $\Delta \mathrm{b}=8$. All coefficients of the equation less than $\Delta \mathrm{b}$ are assumed to be insignificant and equated to 0 . The polynomial analysis shows that the density of the foam concrete is most affected by the consumption of the foaming agent and to a lesser extent - the increase in the length of the basalt fibers. Thus, the use of short fibers contributes to the reduction of the average density (the coefficient of X2 equal to 20) there is a stabilization of the foam. Using of short fibers contributes to the reduction of the average density (the coefficient of X2 equal to 20) - there is a stabilization of the foam.

The optimal consumption of the complex additive is determined using the analytical optimization method: $\partial \mathrm{Y}_{1} / \partial \mathrm{X}_{2}=-20+24 \cdot \mathrm{X}_{2}=0$, thus $\mathrm{X}_{2}=20 / 24=0,83$.

In real terms, the optimal length of basalt fiber will be:

$$
\tilde{X}_{2}=\bar{X}_{2}+\Delta X_{2} \cdot(0,83)=5+1 \cdot 0,83=5,83 \mathrm{~mm}
$$

Taking into account the accepted probability of predicting a reliable result of $98 \%$, the optimal consumption of a complex additive is $5.8 \pm 0.1 \mathrm{~kg} / \mathrm{m}^{3}$.

We solve the equation $\mathbf{Y}_{1}\left(\mathrm{X}_{2} \mathrm{X}_{4}\right)$ with $\mathrm{X}_{2}=0,83$ :

$$
Y_{1}\left[X_{2}=0,83\right]=560-9 X_{1}-20 \cdot 0,83-60 X_{4}+12 \cdot(0,83)^{2}
$$

We obtain a linear dependence of the average density of cellular concrete from the blowing agent $\left(\mathrm{X}_{4}\right)$ and the flow of mineral fiber $\left(\mathrm{X}_{1}\right)$.

2) the strength of cellular fiber concrete is determined by the following polynomial:

$$
Y_{2}=2,81+0,25 X_{1}+0,12 X_{2}+0,32 X_{3}-0,22 X_{4}-0,11 X_{1} X_{2}+0,13 X_{2} X_{3}-0,09 X_{2} X_{3}
$$

The calculated confidence interval is $\Delta \mathrm{b}=0.06$. To the greatest extent, the strength depends on the flow rate of Portland cement (coefficient at $X_{3}$ is 0.32 ), to a slightly lesser extent from the flow rate and length of basalt fibers and the flow rate of the foaming agent 
(coefficients at $\mathrm{X}_{1}, \mathrm{X}_{2}, \mathrm{X}_{4}$ ). With the increase in the consumption of blowing agent, the strength is reduced (the coefficient of $X_{4}$ is equal - 0,22). Of pair interactions, the most powerful joint influence of the length of the fibers and flow of Portland cement $\mathrm{X}_{2} \mathrm{X}_{3}$ (ratio of 0.13). The calculation results are shown in Fig. 5.

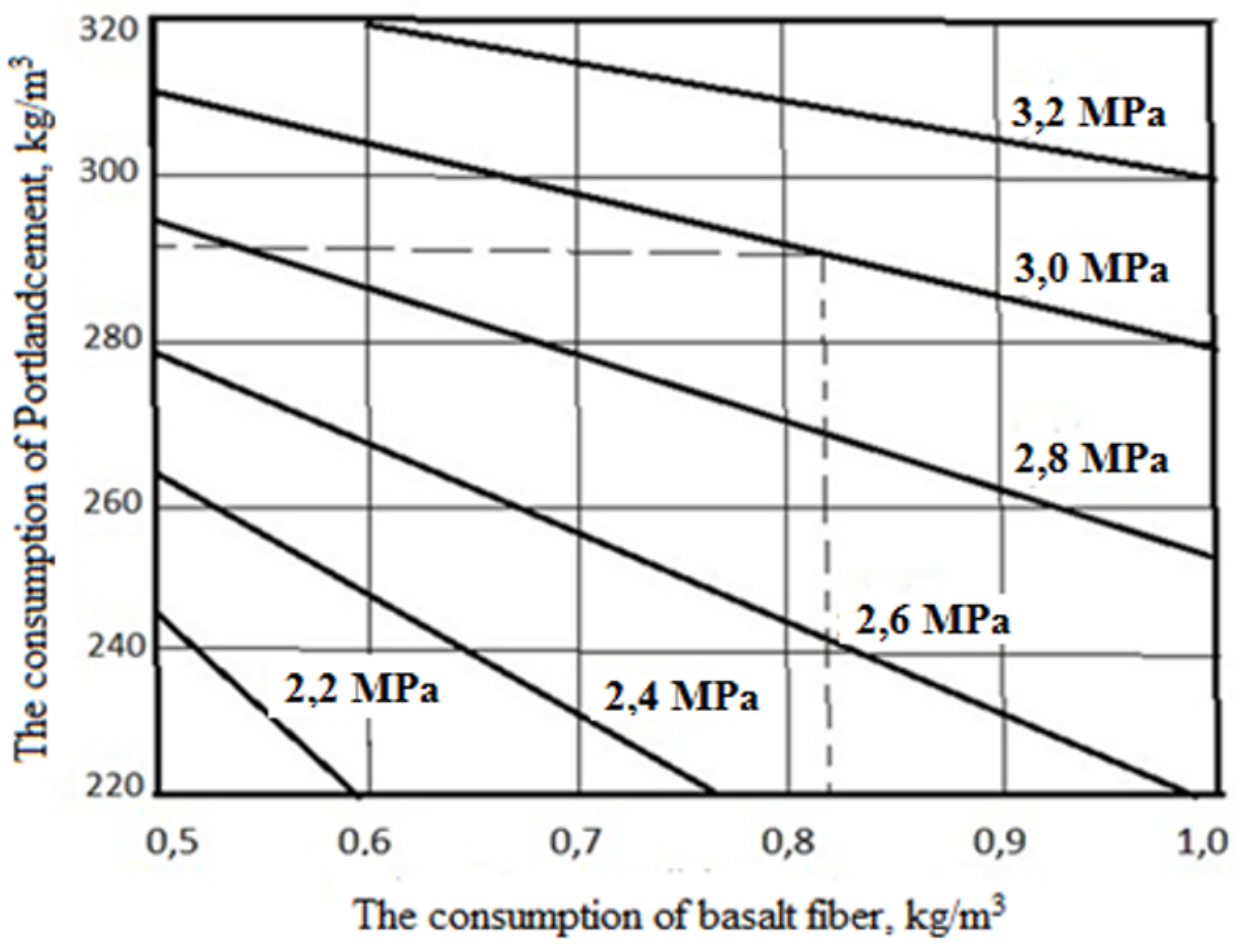

Fig. 5. Determination of the cost of Portlandcement and basalt fiber depending on the required strength of products (with the design average density of $352 \pm 11 \mathrm{~kg} / \mathrm{m}^{3}$ )

5) Taking into account the results of analytical optimization, we solve the equation $Y 2=$ f1(X1X2X3X4) with X2=0,83

$$
Y_{2}\left[X_{2}=0,83\right]=2,88+0,38 X_{3}+0,18 X_{1}-0,22 X_{4}-0,09 X_{1} X_{3}
$$

6) Consumption foaming agent (X4) is determined by calculation. In the model it is equated to the average value (in coded form $\mathrm{X} 4=0$ ).

Y1 becomes equal to $552 \mathrm{~kg} / \mathrm{m} 3$, which, taking into account the accuracy of the experiment (probability 98\%) will be $552 \pm 11 \mathrm{~kg} / \mathrm{m} 3$, and the equation for the strength of the foam concrete becomes final:

$$
Y_{2}=2,88+0,38 X_{3}+0,18 X_{1}-0,09 X_{1} X_{3}
$$

Component expenses and product properties are presented in tables 2 and 3. 
Table 2. Consumption of the main components of cellular concrete reinforced with mineral fiber

\begin{tabular}{|c|c|c|c|}
\hline \multirow{2}{*}{ Components } & \multicolumn{3}{|c|}{ Consumption, $\mathrm{kg} / \mathrm{m}^{3}$ for density grade } \\
\hline & D 300 & D 400 & D 500 \\
\hline Portlandcement M 500 & 210 & 240 & 270 \\
\hline The consumption of mineral fiber & 0,80 & 0,75 & 0,70 \\
\hline fraction sand & 30 & 70 & 110 \\
\hline foamer & 0,45 & 0,40 & 0,35 \\
\hline water & 180 & 210 & 250 \\
\hline
\end{tabular}

Table 3. Product properties

\begin{tabular}{|l|c|c|c|}
\hline \multirow{2}{*}{\multicolumn{1}{|c|}{ Indicators }} & \multicolumn{3}{c|}{ Grade density, $\mathbf{~ k g} / \mathbf{m}^{\mathbf{3}}$} \\
\cline { 2 - 4 } & D 300 & D 400 & D 500 \\
\hline Length $\times$ Height, $\mathrm{mm}$ & \multicolumn{3}{|c|}{$600 \times 250$} \\
\hline Thickness, mm & 200 & 300 & 400 \\
\hline Strength class & B 2,0 & B 2,5 & B 3,0 \\
\hline Thermal conductivity, $\mathrm{W} /(\mathrm{m} \cdot \mathrm{K})$ & 0,10 & 0,12 & 0,15 \\
\hline Frost resistance & F 35 & F 50 & F 50 \\
\hline
\end{tabular}

Figure 6 shows a nomogram that allows to determine the consumption of basalt fiber depending on the required strength of products and consumption of Portlandcement.

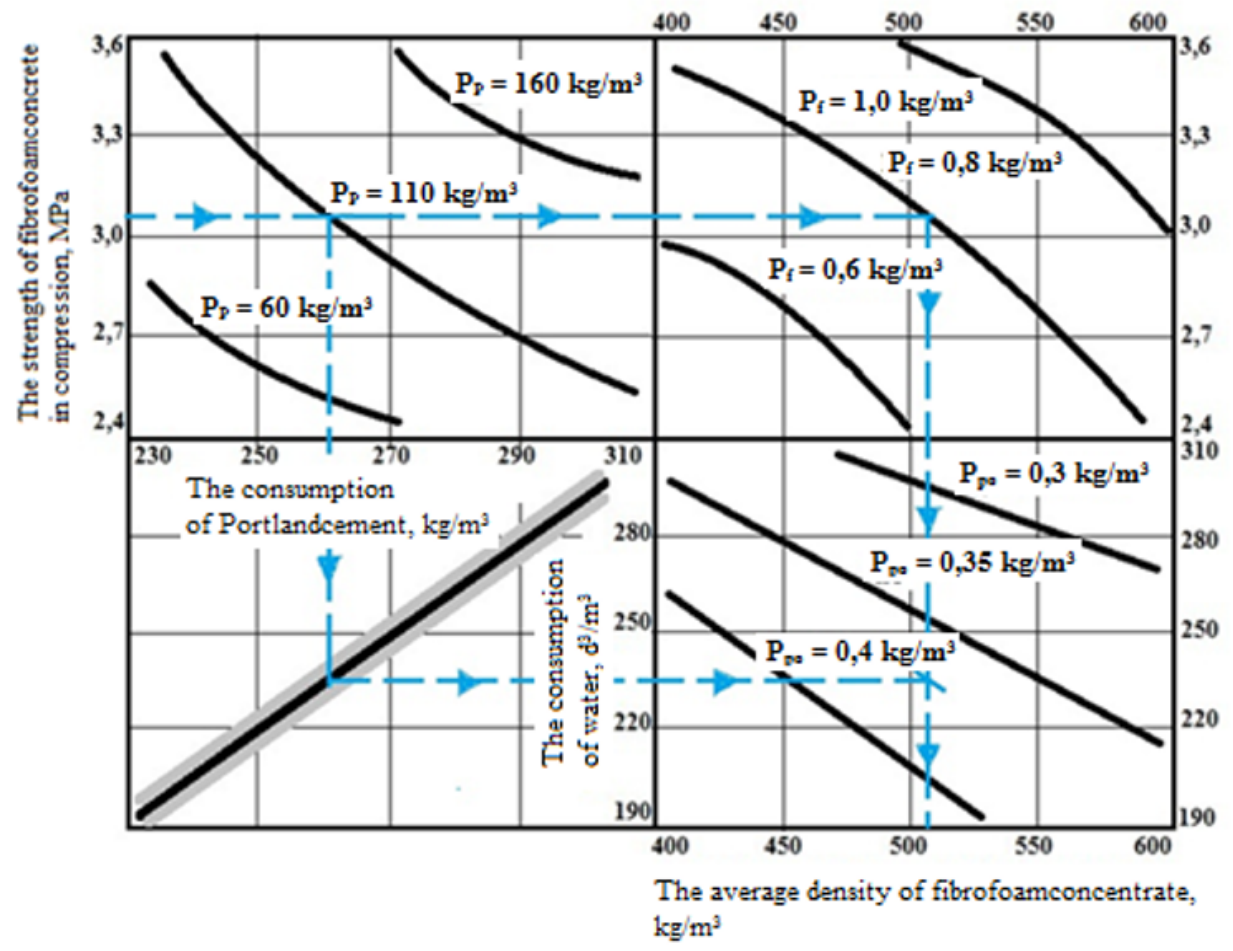

Fig. 6 Nomogram for the selection of the composition

As a result of the experiment, it was found that the consumption of basalt fiber affects both the strength and the density of cellular concrete products. The length of the basalt fiber 
affects only the strength of the products. The effect of Portlandcement and mineral fiber consumption on the strength characteristics of the material and its average density is studied. For convenience of use, the equations are presented in graphical form and are designed in the form of a nomogram.

\section{Conclusions}

The main advantages of using mineral alkali-resistant fiber for concrete and cellular concrete blocks are that even a small addition of these fibers can increase the resistance of structures to flexure loads. Reinforced concrete blocks made of cellular concrete are characterized by high resistance to impact loads, incombustibility and resistance to vibration. Alkali-resistant mineral fiber prolongs the useful life of buildings, reduces their shrinkage deformation and reduce crack formation. Blocks of cellular concrete, reinforced with alkali-resistant mineral fiber, can reduce the total weight of building structures, labor costs for reinforcement works and reduce construction time. Adding waste concrete allows to achieve high economic results without significantly reducing the basic properties of the product.

Mineral fiber-reinforced structures can be built on weak soils and effectively solve the problems of saving energy and raw materials. If you add up all the benefits of dispersed reinforcement, they concluded to reduce the economic cost of the objects construction, providing their reliable and durable exploitation.

\section{References}

1. H. Zhuk, A. Zhukov Normative legal base of environmental assessment of building materials: prospects for improvement // Ecology and industry of Russia. 4 52-57. (2018)

2. M. Bezdenezhnykh, E. Munieva, A. Zhukov. Building materials and ecology, Persp. of sc. 11. 33-36 (2017)

3. B. Rumyantsev, A. Zhukov, T. Smirnova Energy efficiency and methodology for creating heat-insulating materials // Internet-Vestnik VolgGASU. 43 (2014)

4. B. Rumiantcev, A. Zhukov, E. Bobrova, I. Romanova, D. Zelenshikov, T. Smirnova MATEC Web of Conferences 86 (2016)

5. A. Zhukov, I. Romanova, S. Isachenko, M. Kodzoev, A. Yu. Zhukov. // Innovation in life 2 229-234 (2017)

6. A. Zhukov, S. Kozlov, V. Koridze, M. Burtseva, E. Mednikova // Innovations in life. 2 250-259 (2017)

7. A. Medvedev, A. Zhukov, E. Bobrova, E. Petrovskiy, D. Tuchaev // Science and business: ways of development. 10 35-38 (2017)

8. I. Tolokonnikov, Energodispersionnyy rentgenofluorescentnyy analizator sostava vechestva ReSPECT, Atom. en. 95 69-70 (2003)

9. A. Medvedev, E. Bobrova, A. Poserenin, E. Zarmanyan MATEC Web of Conferences 170 (2018)

10. A. Medvedev, A. Poserenin, Application of energy dispersive X-ray spectrometers for elemental analysis of geological samples, Min. Info. and an. Bul. 11 115-124 (2016)

11. A. Medvedev, M. Gurvich, A. Poserenin The application spectrometr ReSPECT for analysis of the element composition of minerals, rocks and ores Mat. of XII Int. sc. and prac. conf. «New ideas in earth sciences» 147 (2015) 